\section{Do local ao regional e vice- versa: imagens do Alto Xingu}

Bruna FRANCHETTO e Michael HECKENBERGER (orgs.). Os povos do Alto Xingu: história e cultura. Rio de Janeiro, Editora da UFRJ, 2001. 492 páginas.

\section{Renato Sztutman}

Desde a expedição de Karl Von den Steinen, em 1884, o Alto Xingu tem sido alvo de inúmeras especulações, especialmente pela situação etnográfica singular que apresenta, ou seja, "uma plataforma giratória que coloca em relação às culturas mais diversas e as mais afastadas da América Tropical”, para mencionar as palavras de Claude Lévi-Strauss (apud artigo de Monod-Becquelin e Guirardello, p. 404). De fato, quando Karl Von den Steinen chegou à região, o sistema intercomunitário (para não dizer intertribal) que hoje nos desperta interesse já estava praticamente consolidado: grupos de diferentes famílias lingüísticas (aruak, caribe, tupi e trumai) estabeleciam vastas e complexas redes de intercâmbio envolvendo casamentos, rituais e trocas materiais, sem perder de vista a autonomia política de seus grupos locais quadro esse, vale notar, algo diverso dos demais da região amazônica. É sobre essa imagem primeva de um sistema articulado que os quinze artigos da presente coletânea procuram se debruçar, lançando-se numa missão inquietante, qual seja, a de compreender os processos que levaram à constituição desse sistema.

Uma das virtudes da coletânea é a sua opção pela interdisciplinaridade que, aliás, pode ser reconhecida como característica dos estudos alto-xinguanos realizados nos últimos cinqüenta anos. A antropologia, disciplina privilegiada no tratamento de povos não-ocidentais (ou não-modernos, como prefere Bruno Latour), tem aqui de interagir com disciplinas vizinhas clássicas, como a arqueologia, a história e a lingüística. Não por acaso, os organizadores, Bruna Franchetto e Michael Heckenberger, são, respectivamente, pesquisadores das áreas de lingüística e arqueologia que fazem de sua formação antropológica um campo de debate intri- gante. Além das já mencionadas, há discussões com a biologia, a geografia política e a teoria da arte (com foco nas artes gráficas e na música). No que se refere à antropologia propriamente dita, a coletânea explicita o embate entre posturas teóricas reconhecidas como conflitantes, tais a tradição culturalista-difusionista que gerou, entre outras coisas, os estudos de ecologia cultural e a tradição estrutural-funcionalista, que tem se mostrado hegemônica nos estudos amazônicos das últimas três décadas. Ora, a heterogeneidade de abordagens, a princípio desconcertante, revela o mérito de poder apreender um fenômeno de tamanha complexidade não apenas por meio de uma lente viciada, mas pela multiplicidade de pontos de vista, mesmo que disso resulte a ausência de consenso sobre a imagem a ser veiculada.

Mas se os caminhos são múltiplos, o problema permanece o mesmo para os autores de formação diversa: não é possível pensar a realidade alto-xinguana sem apelar para a história. Ao contrário de outras paisagens etnográficas na região em foco, o sincronismo dos estudos monográficos não satisfaz o pesquisador diante da formação de um sistema em que as divergências culturais cedem em favor da constituição de um espaço de partilha de práticas e concepções. A antropologia, na virada do século XX, aprendeu bem a lição de Radcliffe-Brown e Claude Lévi-Strauss de que a especulação sobre as origens e a difusão de traços culturais é vã quando não se têm meios para efetivar uma análise dotada de rigor científico. Não obstante, os avanços da lingüística histórica (ainda incipientes no Alto Xingu, como pontua Franchetto, no capítulo "Línguas e história no Alto Xingu") e da etno-arqueologia têm se mostrado satisfatórios para indicar novos caminhos para velhas questões. Trata-se de expurgar a história conjectural para encontrar novos meios de fazer história entre (ou com) os povos indígenas. Ora, isso implica propriamente um diálogo entre o recurso a uma macrohistória, capaz de desvelar processos longos que ultrapassam a consciência dos agentes, e a uma microhistória, que emerge da investigação das várias tradições orais e concepções locais de causalidade e temporalidade. 
O subtítulo do livro - "História e cultura" - é revelador dos propósitos dos organizadores. Tratase de entender o que vem ser a "cultura" (ou, em outros momentos, a "sociedade" ou o "sistema", termos flutuantes) partilhada pelos povos alto-xinguanos através do tempo, reconstituir o que se poderia chamar de uma "história cultural" alto-xinguana. Na "Introdução", os organizadores falam em uma "antropologia histórica dos índios xinguanos" (p. 7) que deve se preocupar em desvendar "o que fez os xinguanos serem o que são e como isso aconteceu", posto que "não podemos apenas 'espremer' ainda mais os nossos dados etnográficos ou seja, perscrutar mais profundamente o presente; é preciso abordar também o passado [...]. 'Fazer' história requer, portanto, a articulação entre uma história objetiva - a história dos objetos (artefatos e textos) - e uma história subjetiva - representada nos corpos, nas ações, nas memórias e nos saberes dos próprios xinguanos" (p. 9).

A estrutura da coletânea é também reveladora. Esta se divide em duas partes: a primeira trata de visões regionais, ou seja, procura se referir, de maneira por vezes desconfiada, a uma "sociedade" ou "cultura" alto-xinguana tomada no singular; a segunda, de visões locais, buscando restituir a perspectiva dos grupos particulares sobre o conjunto maior no qual se vêem inseridos. A coletânea principia com um artigo de Michael Heckenberger sustentando a tese da continuidade de um "padrão cultural" aruak que viria a transformar os outros grupos chegados posteriormente à região de maneira a constituir uma "sociedade" por assim dizer una. Já os três últimos artigos - de Rafael José de Menezes Bastos ("Ritual, história e política no Alto Xingu: observações a partir dos Kamayurá e do estudo da festa da Jaguatirica"), Marcela Stockler Coelho de Souza ("Virando gente: notas para uma história aweti") e Aurore Monod-Becquelin e Raquel Guirardello ("Histórias Trumai") - trazem reflexões justamente sobre os últimos grupos a chegar ao Alto Xingu, aqueles de língua tupi e trumai, centrando-se na questão da memória de sua incorporação no sistema; memória, ressaltam os autores, que continua a atuar no presente de modo a estabelecer uma certa distinção diante de um suposto processo de homogeneização. A coletânea, assim, abriga duas imagens não excludentes, porém conflitantes, em torno das quais os artigos oscilam. De um lado, busca-se a imagem de uma "sociedade" ou "cultura" delimitada, apreensível de um único ponto de vista, para o qual converge todo o movimento. De outro, busca-se a especificidades dos diferentes pontos de vista sobre essa suposta "sociedade" ou "cultura", cujos contornos já não são tão nítidos, mas variáveis e fugidios.

Consideremos a primeira imagem, mais fortemente presente nos artigos de Heckenberger ("Estrutura, história e transformação: a cultura xinguana na longue durée, 1000-2000 D.C." e "Epidemias, índios bravos e brancos: contato cultural e etnogênese no Alto Xingu"). O primeiro artigo se lança em uma rigorosa reconstrução arqueológica do "padrão cultural" alto-xinguano, tendo em vista a noção de estrutura de "longa duração", inspirada em Braudel. O foco se dá na pré-história dos povos da região, ou seja, no período anterior à chegada dos "brancos" ou "caraíbas", para usar um termo largamente empregado por esses povos. Para tanto, o autor propõe uma nova metodologia:

[...] integrar diversos níveis da análise, derivados não apenas da observação etnográfica, das narrativas indígenas e das fontes documentais, mas também do estudo arqueológico de resíduos materiais, criados pela ação humana no passado [...] tentar revelar e relacionar padrões relevantes visíveis em níveis analíticos diferentes (ou seja, relativos a escalas espaço-temporais variáveis), buscando entender a história e a cultura num sentido holístico; em outras palavras, trata-se de criar um diálogo conceitual entre modos diferentes de pensar a história (p. 25).

O segundo artigo dedica-se à história do contato com o "mundo dos brancos", que cobre os cinco séculos posteriores ao "descobrimento" e se intensifica no final do século XIX, sendo marcada por inúmeras epidemias e, conseqüentemente, baixas populacionais. Ora, se o primeiro artigo busca evidências da constituição de uma "estrutura" ou "padrão" (termos igualmente oscilantes no autor) na longa duração, o segundo procura verificar como essa estrutura desembocou, quando submetida a processos históricos determinados, 
na formação da sociedade alto-xinguana como vislumbrada atualmente.

Heckenberger recoloca-nos diante de uma das questões fundantes da antropologia: o contato intercultural. E o Alto Xingu se oferece como paisagem privilegiada para tamanha reflexão. A pergunta que ecoa é o que exatamente, na "cultura" indígena, pode ser considerado inato/duradouro ou adquirido/transformado pelo contato com outras "culturas". No Alto Xingu, entretanto, esse contato não diz respeito apenas à sociedade nãoindígena ou nacional, mas sobretudo àquele entre diferentes "culturas" indígenas. Note-se que o autor preserva um vocabulário fortemente culturalista, reafirmando a noção de "cultura" como algo descontínuo em si mesmo e contínuo no tempo, o que lhe permite flertar com temas como "aculturação" e "difusão". Pontuando algumas ilusões do presente etnográfico, sua abordagem retoma as origens da "sociedade"/“cultura" alto-xinguana, desta vez capturadas por uma metodologia rigorosa. Essas origens, prossegue o autor, só podem ser compreendidas quando identificados os centros de difusão, tal a Periferia Meridional Amazônica, que em determinado momento reuniu diversos grupos aruak, entre os quais se poderia identificar uma estrutura prototípica que teria sido imposta, gradualmente, aos outros grupos que foram se agregando à chamada região do Uluri, como os Tupi e os Trumai.

Heckenberger distancia-se da noção de "aculturação intertribal", empregada por Steinen, que ressalta o sentido simétrico da formação de um todo compósito por meio da diluição, por igual, das especificidades das partes em jogo. Para Heckenberger, assim como para Gertrude Dole ("Retrospectiva da história comparativa das culturas do Alto Xingu: um esboço das origens culturais alto-xinguanas"), o que houve de fato foi um processo assimétrico, no qual práticas e concepções adotadas pertenciam a grupos cujo poder e prestígio eram superiores - grupos aruak caracterizados por sua complexa organização espacial (aldeias grandes e fortificadas) e chefaturas hierarquizadas. Assim, para o autor, "a aculturação 'intertribal' não foi a responsável pelo padrão xinguano, mas, antes, a transformação de um padrão monolíngüe para um tipo plural regional" (p. 88). O modelo apresentado é claramente centrípeto - "O locus da fecundidade social é o interior" (p. 91): as especificidades culturais dos grupos caribe (cuja integração ao sistema aruak data do período entre os séculos XVII e XVIII), dos grupos tupi (que chegam ao Alto Xingu em meados do século XVIII) e dos Trumai (estabelecidos na região apenas no século XIX) vão se perdendo à medida que estes passam a se incluir - se "acomodar", para usar o termo do autor - em redes de relações de escala supralocal que dariam lugar à constituição de um "padrão cultural" singular, que pode ser vislumbrado na organização espacial das aldeias atuais, na participação e na execução de certos rituais intercomunitários ou na recorrência a certos padrões gráficos (ver, sobre esse último aspecto, o artigo de Aristóteles Barcelos Neto, "Apontamentos para uma iconografia histórica xinguana").

Heckenberger entende por "padrão cultural" o conjunto de aspectos como organização espacial, economia de subsistência e tecnologia, guiando-se pelos critérios de medição em arqueologia e pela noção de habitus empregada por Pierre Bourdieu. No caso do "padrão cultural" aruak revelado na longa duração, ele identifica três elementos básicos: 1) o sedentarismo implicado em um padrão de assentamento rígido; 2) a hierarquia implícita na estrutura sociopolítica intra-aldeia e baseada na distinção entre chefes e comuns; 3) a regionalidade resultante da interdependência entre as aldeias para a realização de rituais de passagem e da partilha de códigos morais ou mesmo concepções comuns de humanidade. Como pontua Emilienne Ireland ("Noções waurá de humanidade e identidade cultural"), a categoria putaka (aruak) ou kuge (caribe), "alto-xinguanos", remete a valores morais compartilhados que permitem a distinção com os índios "bravos" ( $m u$ teitsi ou angikobo, respectivamente waurá [aruak] e kalapalo [caribe]) e os brancos (kajaiba ou $k a-$ raiba, idem). Os últimos enquadrar-se-iam em uma categoria "menor" de humanidade, ao passo que a humanidade por excelência caberia aos alto-xinguanos. Sendo assim, a incorporação dos grupos não-aruak não se resume a empréstimos, mas diz respeito à "adoção de cosmologias e ideo- 
logias distintas" (Heckenberger, p. 90), e, portanto, a uma mudança de sentido.

Se o regionalismo e sua ideologia pacifista são padrões inscritos na longa duração - a mitologia de grupos aruak, como os Mehinaku, são uma evidência desse aspecto, como aponta Thomas Gregor ("Casamento, aliança e paz intertribal") - para entender a constituição da "sociedade" xinguana atual é preciso entender por que grupos beligerantes, como os Tupi e os Trumai, sucumbiram a esses valores. A tese de Heckenberger é a de que a baixa populacional provocada pelas terríveis epidemias no fim do século XIX proporciona a condição histórica para a incorporação e as assimilações dos outros grupos. Em outras palavras, Heckenberger explica a constituição da sociedade alto-xinguana pela combinação entre as forças centrífugas do colonialismo e a força centrípeta dos grupos aruak, e, nesse sentido, o declínio demográfico propiciou a diluição das fronteiras que separavam grupos distintos para, então, criar uma nova fronteira, aquela que separa os alto-xinguanos do restante das sociedades indígenas de seu entorno e da sociedade nacional brasileira. É nesse contexto de um jogo entre forças divergentes que Heckenberger vislumbra, enfim, a "etnogênese da sociedade pluriétnica altoxinguana” (p. 109), a construção de uma categoria distintiva e, por assim dizer, definitiva, que engloba as distinções prévias.

A ênfase na constituição da identidade altoxinguana ganha aporte na antropologia biológica. Ricardo Ventura dos Santos e Carlos E. A. Coimbra ("'Parece feito por molde único': cultura, sociedade e bioantropologia no Alto Xingu") sugerem que as interações culturais repetidas em uma determinada área propiciam a manutenção do intercâmbio genético ("fluxo gênico") entre as comunidades. Por meio de dados antropométricos, coletados inicialmente por Ehrenreich (integrante da expedição de Steinen), os autores concluem que os alto-xinguanos são "morfologicamente mais afins entre si e tendem a se diferenciar dos outros grupos indígenas do Brasil Central que não participam do chamado sistema cultural xinguano" (p. 169). Haveria entre estes uma tendência à homogeneização ("amalgamento") biológica que se deve à combinação do isolamento geográfico e da dinâmica evolutiva associada predominantemente aos intercasamentos. Tudo se passa então como se no Alto Xingu tivesse sido esculpido como um "tipo antropológico único", um "molde único", para citar a referência dos autores a Euclides da Cunha em Os sertôes.

Suspeitas em relação ao modelo "autocontido" alto-xinguano reivindicam uma outra imagem, na qual a identidade regional permanece incompleta e o estado de paz é constantemente posto em xeque pelos conflitos internos e externos; o sentido da comunidade moral é ameaçado pelas práticas de feitiçaria e a fronteira fortemente demarcada entre povos do Uluri e povos marginais parece diluir-se em zonas de intercâmbios. Autores como Bastos, Barcelos Neto e Coelho de Souza recuperam os argumentos de Patrick Menget (que infelizmente não escreveu para a coletânea), que recusa aprisionar os povos do Alto Xingu em um rótulo de pacifismo em contraposição a outros, supostamente belicosos. Que fazer, nesse sentido, com a tradição bélica de povos como os Tupi e os Trumai? Aceitar simplesmente a tese da aculturação assimétrica? Como pontua Bastos (apud artigo de Coelho de Souza, p. 393, nota 20), o congelamento do quadro bélico aludido não pode ser compreendido fora do contexto da ação indigenista liderada pelos irmãos Villas Boas, que redundou na criação do Parque Indígena do Xingu (PIX).

O único dos artigos a analisar criticamente a criação do PIX é o de Maria Lúcia Pires Menezes ("Parque do Xingu: uma história territorial"). A geógrafa atenta para o deslocamento da história da gênese das sociedades da região do Uluri, região marcada por um estado de relativo isolamento geográfico e difícil acesso, para a de um novo território construído pela articulação política entre o Estado brasileiro, o Estado do Mato Grosso, a política indigenista e os interesses econômicos sobre as terras em questão. A tese da autora é a de que

[...] não obstante a aparente defesa das condições geográficas como fator relevante para a estabilidade político-territorial de cada grupo étnico, promoveram-se mudanças da localização da maioria das aldeias, num acinte de negação de preceitos que respeitem a integridade política e social (p. 237). 
A autora acusa os irmãos Villas Boas de "engenharia indigenista", que culminou na recriação de aldeias, como a yawalapiti, cujos membros se encontravam dispersos, e na criação de um pólo de atração ao redor do Posto Leonardo, sempre sob o intuito de fomentar a ampliação de redes intercomunitárias e diluir diferenças e disputas internas. Nesse sentido, os irmãos Villas Boas teriam interferido "de modo crucial nas relações políticas dos grupos indígenas da região dos formadores, principalmente na intermediação do contato entre estes e os situados mais ao norte, na área de influência do posto Diauarum (Suyá, Juruna, entre outros)" (p. 238).

A apreensão do espaço de relações intercomunitárias como absolutamente homogêneo é, para a autora, resultado não apenas de um "indigenismo isolacionista", que supõe a paralisação de tempo e espaço, mas também da criação de elos de dependência econômica e do esforço para extinção das rivalidades expressas por uma belicosidade explícita. Para a autora, a idéia de igualdade entre os povos vem do exterior, do fato de que os grupos são tratados do mesmo modo pelos brancos. A crítica da construção do território alto-xinguano esclarece, pois, um aspecto do artificialismo da imagem da homogeneidade, sem tocar, no entanto, na dinâmica das relações intercomunitárias no interior do "sistema". Esse ponto, à sua parte, é tratado por Rafael Menezes Bastos em sua análise sobre o complexo ritual alto-xinguano, e mais especificamente sobre o Jawari, festa de lançamento de dardos introduzida pelos Trumai.

Bastos refere-se ao Alto Xingu como um sistema de comunicação entre "nem simplesmente iguais ou semelhantes, nem tão-somente diferentes" (p. 339). Trata-se de um sistema aberto e movente, que incorpora os povos "marginais" ou "xinguenses" - Ikpeng, Suyá, Juruna e Kayabi -, os "caraíbas" - funcionários do PIX, indigenistas, agentes da educação bilíngüe, entre outros - e os Bakairi - povo que viveu na região do Uluri até os anos 1940 e que guarda uma memória acentuada das relações ali estabelecidas, como evidencia Edir Pina de Barros ("Os Bakairi e o Alto Xingu”). Quanto aos povos "marginais", é importante lembrar o que escreve Gregor, nessa coletânea, sobre os casamentos não tão raros com os wara$j u$ ("índios bravos", em mehinaku): tais práticas, embora não muito comuns, podem ser lidas na chave do mito da "oferenda de mulheres ao jaguar" (p. 181), cuja mensagem consiste na idéia de que o casamento com membros de grupos estranhos é a melhor maneira de estabelecer a paz. Processo pacifista ou não, o importante, salienta Bastos, é apreender a "xinguanização" em termos de uma "aceitabilidade comunicatória", uma possibilidade incessante de inclusão das diferenças. O importante é, então, pensar o Alto Xingu como síntese provisória - síntese que integra mas não igualiza - de diversos pontos de vista, que podem ser colhidos quando da análise, entre outras coisas, de diferentes manifestações rituais.

O ritual intercomunitário alto-xinguano implica uma forma não-verbal de comunicação, como ressalta Bruna Franchetto na segunda parte de seu artigo. Isso porque se os alto-xinguanos são multilíngües, eles não são, ao menos em princípio, poliglotas; ou seja, as línguas faladas por cada grupo local não são inteligíveis por todos os membros que participam do ritual. A autora sugere que a comunicação nessas instâncias não se dá entre entidades que se querem idênticas, mas que, ao contrário, insistem em demarcar suas diferenças, fazendo-o, no mais das vezes, por meio da língua. Com efeito, não se verifica, como em outras paisagens etnográficas, a adoção de uma língua franca. Apenas os grupos locais podem ser considerados "comunidades de fala", sendo a interação verbal restrita a situações pessoais, o que revela um paralelismo com a preferência por alianças matrimoniais, seja no interior do próprio grupo local, seja com um grupo local falante de uma língua da mesma família lingüística. Os alto-xinguanos, segundo a autora, atribuem uma diferença entre falar, que é um emblema do pertencimento a um grupo, e entender, ouvir e compreender, pois "se é proibido falar a língua dos outros, é possível falar cantando diante dos outros e cantar a língua dos outros" (p. 146). Ora, a evitação de falar a língua dos outros remete ao comportamento entre afins, marcado pela reserva e pelo perigo. Nas festas intercomunitárias, em que reina a afinidade, os cantos, que podem misturar línguas diferentes, e a música são os idiomas básicos. 
É nesse contexto que Bastos, preocupado com o ponto de vista dos povos de língua tupi (sobretudo dos Kamayurá) sobre o sistema maior, apresenta o Jawari, ritual composto por uma complexa seqüência de cantos, todos eles envolvendo a figura de bravos guerreiros. Como o Kwarup (infelizmente não analisado nessa coletânea), o Jawari homenageia membros falecidos de grande importância. Mas se o primeiro, de origem aruakcaribe, celebra o ideal da chefia, repondo a distinção básica entre chefes e comuns; o segundo, de origem tupi-trumai, comemora os ideais da atividade guerreira centrando-se na figura dos arqueiros campeões (lançadores de dardos), homens comuns. Diz-se, no Alto Xingu, que o Jawari é atividade de "índios bravos" e remonta ao grupo antigo Pajetã, que teria ensinado o ritual aos Trumai, que, por sua vez, o ensinaram aos Kamayurá e Aweti. Ora, este ritual, atualmente uma realização pan-xinguana, permanece como distintivo dos povos mais tardiamente chegados à região do Uluri, servindo também de receptáculo para uma memória das vicissitudes passadas, ainda que plena de esquecimento, como acentuam Aurore MonodBecquelin e Raquel Guirardello.

Os artigos de Monod-Becquelin e Guirardello e de Coelho de Souza fazem referência à carência de informações sobre o percurso dos Trumai e dos Aweti antes de sua chegada no Alto Xingu. A classificação dessas línguas evidencia essa dificuldade - o trumai não se enquadra em nenhuma família lingüística conhecida e o aweti parece ser uma língua isolada do tronco tupi (sobre esse ponto, ver a primeira parte do artigo de Franchetto). Não obstante, há uma forte incidência de narrativas na tradição oral sobre guerras, alusões a povos canibais e menções a uma ética alimentar diferente daquela seguida pelos alto-xinguanos atuais. É sob essa perspectiva que Coelho de Souza discute a extensão do conceito (caribe) de ihutisu, comportamento modesto e controlado que deve ser seguido nas relações tanto intra como intercomunitárias. Ellen B. Basso ("O que podemos aprender do discurso kalapalo sobre os Kalapalo?") refere-se, tomando a tradição oral dos Kalapalo, à superação de um passado canibal em favor de um ideal de pacifismo generalizado regionalmente. À ferocidade dos angi- kogo, índios "bravos" ou "selvagens", os Kalapalo preferiram o valor do ibutisu praticado pelos kuge, os verdadeiramente humanos. Ora, o que para Basso parece ser uma ideologia difundida e totalmente compartilhada, para Coelho de Souza parece ser invadido por uma oscilação que inclui o pólo oposto, o do conflito armado. Desse modo, a última, na esteira das considerações de Bastos, problematiza a expansão do "locus do julgamento ético" para tomar a beligerância como "possibilidade estruturalmente inscrita no sistema xinguano, e tão definidora de seu caráter quanto a situação pacífica dos encontros cerimoniais" (p. 370).

Coelho de Souza, ao partir dos Aweti para alcançar uma visão mais ampla da configuração sociopolítica alto-xinguana, revê o lugar (eclipsado pela literatura) das práticas de feitiçaria, atividade que resulta de conflitos internos e que mobiliza uma dinâmica faccional de incorporação e expulsão de pessoas no seio dos grupos locais. Para a autora, a feitiçaria seria um operador de abertura do sistema, e não um mecanismo de "paz negativa", como indica Gregor, tampouco um limite para o poder dos chefes. Trata-se, sob esse ponto de vista, de um elemento constitutivo da ação política alto-xinguana, ao contrário do que sugere Heckenberger, que vê aí um conjunto de ações relegadas à contingência e à esfera individual. Desse modo, para Coelho de Souza, pensar a política no Alto Xingu implica a apreensão de uma dialética entre a unidade da aldeia no ritual intertribal, simbolizada pelo chefe, e o fracionamento que rege as acusações de feitiçaria, visto que "a 'integração' de cada 'grupo' no 'sistema' passa pela sua própria ‘desintegração' e 'reintegração'” (p. 388).

A imagem proposta pela autora é alternativa à de Heckenberger, pois desconfia não apenas da direção unívoca e centrípeta do sistema em relação a um padrão cultural singular, mas também da própria integridade dos grupos locais, que se apresentam como unos apenas quando defrontados com outros grupos locais. Isso tudo revela uma tendência centrífuga inegável, que põe em xeque as noções de "sociedade" e de "cultura" como entidades autocontidas e claramente demarcadas. O artigo de Coelho de Souza restitui, com efeito, a crítica estruturalista ao modelo da "socie- 
dade" alto-xinguana, inviabilizando uma abordagem que dê conta do todo dessa "sociedade", visto que qualquer visão perseguida estará sempre vinculada a uma parte específica, a um ponto de vista irredutível. Tal a provocação da autora: olhar a região pelo viés de um povo de origem quiçá tupi, dado que sequer essa última informação pode ser tomada como certa. A imagem do núcleo duro da "cultura" cede à do caleidoscópio das "culturas". Entre uma e outra, o leitor oscila, tateando uma arquitetura que permanece parcialmente velada.

Mas essa oscilação confere virtude ao conjunto dos artigos reunidos, sobretudo porque faz dialogar abordagens diversas ao apresentar contrapontos para os consensos mais diversos. Conclui-se, então, que, se a coletânea não oferece uma imagem, por assim dizer, fechada sobre o sistema alto-xinguano, ela deixa indicado, ao menos, certos atalhos e trilhas decisivos que cabe às análises vindouras percorrer.

\section{RENATO SZTUTMAN é doutorando em} Antropologia Social pela Universidade de São Paulo. 